\title{
2021 ABME Paper Awards
}

\author{
PUBLISHED ONLINE 18 JANUARY 2022
}

Each year, the top papers in Annals of Biomedical Engineering (ABME) are selected for editorial awards that are presented at the annual Biomedical Engineering Society (BMES) meeting. During the 2021 BMES Annual Meeting, a total of five awards were presented: one award for the most citations, ${ }^{4}$ one award for the most downloads, ${ }^{5}$ and three editor's choice awards. ${ }^{6,7,11}$ These papers were selected from a total of 225 papers published in 2020 . While the citation and download awards were selected purely quantitatively, the editor's choice awards were selected by the Editor-in-Chief and Deputy Editors-in-Chief based on overall impact and quality of the papers. The awards covered a wide range of topics in tissue engineering and regenerative medicine, biomechanics, and additive manufacturing.

Cramer and Badylak reviewed extracellular matrixbased biomaterials derived from mammalian tissue for tissue regeneration. ${ }^{4}$ Tissue-derived extracellular matrix has the appropriate microstructure for tissue regeneration, ${ }^{8}$ but clinical outcomes following implantation are highly dependent on the source of the tissue and bioscaffold preparation methods. The source of the tissue can vary in species, anatomic site, and donor age. Preparation methods including decellularization and post-decellularization processing influence the immunogenicity, cell recruitment, and application of the bioscaffold. Since commercial products vary in tissue source and preparation methods, a wide range of clinical outcomes have been documented.

Donnely et al. provided an overview of tissue engineering approaches to breast reconstruction. ${ }^{5}$ Breast cancer is the most frequently diagnosed cancer in women, and most women undergo surgical removal of the primary tumor after diagnosis. ${ }^{1,10}$ Breast reconstruction following mastectomy or lumpectomy to remove breast cancer most commonly involves either an autologous tissue flap or implant. Breast reconstruction with tissue engineering constructs has shown promise for minimizing complications that occur with conventional methods. Most studies to date have been in vitro or animal models evaluating either bioscaffolds or synthetic scaffolds. Stem cells and growth factors have been added to scaffolds to improve tissue regen- eration, but adequate vascularity remains a major challenge for large tissue volumes.

Kim et al. developed a gelatin methacryloyl stiffness gradient hydrogel to study stem cell mechanosensation and differentiation, and the influence of substrate stiffness on cell type and morphology. ${ }^{6}$ Substrate stiffness is known to influence cell differentiation and behavior. ${ }^{12}$ Hydrogel stiffness was correlated with cell aspect ratio, mechanomarker expression, and stiffness. The hydrogel developed here showed promise for screening stem cell behavior as a function of substrate stiffness.

Liu et al. evaluated the laboratory performance of five instrumented mouthguards frequently used by researchers. ${ }^{7}$ Instrumented mouthguards have become increasingly common in studies of head impact biomechanics in sports. ${ }^{2,9}$ The authors simulated football impacts with a pneumatic ram and instrumented dummy head, and found that all mouthguards accurately measured head kinematics. Error in measurements varied by impact location but not impact speed. Additionally, mouthguards with a long enough sampling window during impact could be used to predict brain strain with a convolutional neural network brain model.

Tejo-Otero et al. reviewed applications of additive manufacturing to preoperative surgical planning. ${ }^{11}$ Printing techniques currently used in medicine were summarized, along with advantages and limitations of each technique. 3D printed prototypes for surgical planning can be used for surgical simulations before the procedure if the prototype has appropriate material properties. ${ }^{3}$ Models can also be used for visual planning by the surgeon, or patient education. As 3D printing technologies improve, their applications to surgical planning can contribute to shorter procedure times, better outcomes, and enhanced patient education.

All papers published in ABME during 2021 will be considered for awards to be presented at the 2022 BMES Annual Meeting. Awardees will be notified in July, and invited to receive their awards in person during a plenary session at the meeting. We look forward to recognizing the authors of our most impactful papers at BMES in San Antonio next year, while we also celebrate the 50th anniversary of ABME. 


\section{REFERENCES}

${ }^{1}$ Amirghasemi, F., E. Adjei-Sowah, B. A. Pockaj, and M. Nikkhah. Microengineered 3D tumor models for anticancer drug discovery in female-related cancers. Ann. Biomed. Eng. 24:1-30, 2021.

${ }^{2}$ Bartsch, A. J., D. Hedin, J. Alberts, E. C. Benzel, J. Cruickshank, R. S. Gray, K. Cameron, M. N. Houston, T. Rooks, and G. McGinty. High energy side and rear American football head impacts cause obvious performance decrement on video. Ann. Biomed. Eng. 48:26672677, 2020.

${ }^{3}$ Choi, E., F. Adams, S. Palagi, A. Gengenbacher, D. Schlager, P.-F. Müller, C. Gratzke, A. Miernik, P. Fischer, and T. Qiu. A high-fidelity phantom for the simulation and quantitative evaluation of transurethral resection of the prostate. Ann. Biomed. Eng. 48:437-446, 2020.

${ }^{4}$ Cramer, M. C., and S. F. Badylak. Extracellular matrixbased biomaterials and their influence upon cell behavior. Ann. Biomed. Eng. 48:2132-2153, 2020.

${ }^{5}$ Donnely, E., M. Griffin, and P. E. Butler. Breast reconstruction with a tissue engineering and regenerative medicine approach (systematic review). Ann. Biomed. Eng. 48:925,2020 .

${ }^{6}$ Kim, C., J. L. Young, A. W. Holle, K. Jeong, L. G. Major, J. H. Jeong, Z. M. Aman, D.-W. Han, Y. Hwang, J. P. Spatz, and Y. S. Choi. Stem cell mechanosensation on gelatin methacryloyl (GelMA) stiffness gradient hydrogels. Ann. Biomed. Eng. 48:893-902, 2020.

${ }^{7}$ Liu, Y., A. G. Domel, S. A. Yousefsani, J. Kondic, G. Grant, M. Zeineh, and D. B. Camarillo. Validation and comparison of instrumented mouthguards for measuring head kinematics and assessing brain deformation in football impacts. Ann. Biomed. Eng. 48:2580-2598, 2020.

${ }^{8}$ Padhi, A., and A. S. Nain. ECM in differentiation: a review of matrix structure, composition and mechanical properties. Ann. Biomed. Eng. 48:1071-1089, 2020.

${ }^{9}$ Patton, D. A., C. M. Huber, D. Jain, R. K. Myers, C. C. McDonald, S. S. Margulies, C. L. Master, and K. B. Arbogast. Head impact sensor studies in sports: a systematic review of exposure confirmation methods. Ann. Biomed. Eng. 14:1-11, 2020.

${ }^{10}$ Schwartz, A. D., A. Adusei, S. Tsegaye, C. A. Moskaluk, S. S. Schneider, M. O. Platt, D. Seifu, S. R. Peyton, and C. C. Babbitt. Genetic mutations associated with hormone-positive breast cancer in a small cohort of ethiopian women. Ann. Biomed. Eng. 15:1-9, 2021.

${ }^{11}$ Tejo-Otero, A., I. Buj-Corral, and F. Fenollosa-Artés. 3D printing in medicine for preoperative surgical planning: a review. Ann. Biomed. Eng. 48:536-555, 2020.

${ }^{12}$ Wechsler, M. E., M. Shevchuk, and N. A. Peppas. Developing a multidisciplinary approach for engineering stem cell organoids. Ann. Biomed. Eng. 48:1895-1904, 2020.

\section{BETHANY ROWSON D}

\section{Virginia Tech \\ Electronic mail: browson@vt.edu}

Publisher's Note Springer Nature remains neutral with regard to jurisdictional claims in published maps and institutional affiliations. 